\title{
Extraction and Characterization of Bio-based Polymeric Materials from Traditional Rice Varieties in Sri Lanka
}

\author{
W.G.A. Pabasara, M.P.A. Nanayakkara ${ }^{1}$, A.M.P.B. Samarasekara ${ }^{1 *}$, D.A.S. Amarasinghe ${ }^{1}$ \\ and L. Karunanayake ${ }^{2}$
}

\author{
Department of Materials Science and Engineering \\ University of Moratuwa \\ Sri Lanka
}

\begin{abstract}
Introduction of sustainable and environmentally friendly alternatives for petroleum chemical-based polymers have become one of the most challenging areas of research. Hence, this study addresses the issue by suggesting a more convenient approach to isolate a bio-based polymer cellulose using rice straw as the source of extraction. This study attempts to extract high purity cellulose from the most abundantly cultivated traditional rice varieties namely, Suwandel and Raththal. A three-step chemical purification process, namely dewaxing, delignification, hemicellulose and silica removal was used in this study. The accuracy of the extraction method was verified by utilizing Fourier-transform infrared spectroscopy. Furthermore, a morphological study of extracted cellulose was conducted using scanning electron microscopy. Results showed that Suwandel and Raththal varieties could produce approximately $35 \%$ and $25 \%$ of cellulose yield, respectively. This study formulated a sustainable approach of replacing synthetic polymer materials with plant-based substance.
\end{abstract}

Keywords: Agricultural waste, bio-based polymers, cellulose, traditional rice varieties

\section{INTRODUCTION}

Polymers play a major role as a highly advantageous material in a wide variety of engineering applications throughout past decades (Rösler et al., 2007;Egodage et al., 2017a; Samarasekara et al., 2014). Among the vast spectrum of polymers, synthetic polymers which are derived from fossil hydrocarbons are the most abundantly utilized polymeric materials (Rios et al., 2007). Recent estimates indicated a total production of 8300 million metric tons of synthetic polymers (Geyer et al., 2017). Despite the increasing demand, the non-biodegradable nature of synthetic polymers causes a risk to the human life and the global eco-system (Barnes et al.,2009; Samarasekara et al., 2014). Pynthetic polymers based products have caused many problems such as landfilling and negative impacts to aquatic animals. Further, open burning of polymeric waste has resulted in negative feed backs on the climatic (Lemieux et al., 2004, Moore, 2008) and health hazard to living organisms. It has been predicted that if the current production and waste management trends continue, by 2050 approximately 12,000 metric tons of Polymeric materials will be accumulated in landfills and the natural environment (Geyer $e t$ al., 2017). Hence, introduction of environmentally friendly renewable forms of polymers has become a research priority (Nanayakkara et al,. 2018).

1 Department of Materials Science and Engineering, University of Moratuwa, Sri Lanka

2 Department of Chemistry, University of Sri Jayewardenepura, Sri Lanka

* Corresponding author: banduamp@gmail.com 
Researchers have been able to introduce a new type of materials known as bio-based polymers made from substances extracted from biological substances (Horikoshi et al. ,2005). These materials have the potential to replace synthetically derived polymers while exhibiting superior properties. Some of these materials include cellulose, bioplastics, polylactic acid (PLA) and protein (Iwata et al., 2015, Wool and Sun, 2011). Among them, cellulose can be identified as the most widely available natural biopolymer which is found in a wide variety of sources such as wood, plant fibers, marine animals (tunicate), algae, fungi, and bacteria (Brinchi et al., 2013). Other than being biodegradable, cellulose is biocompatible and has a low density, high aspect ratio, good mechanical properties, low thermal expansion, low toxicity and modifiable surface properties (Siró et al., 2010). These properties and its renewable nature make cellulose as an ideal candidate for a wide variety of potential applications such as reinforcing fibres for nanocomposites, barrier membranes, antimicrobial films, food packaging coatings and edible films, wound dressing and scaffolding materials, artificial implants, and flexible electronics (Habibi et al., 2010). Hence, it is beneficial in many aspects to explore the means of extracting this material by utilizing economical resources and processes.

The agricultural industry of Sri Lanka is one of the sectors which generate large amounts of plant-based residues. It is estimated that approximately 800 gigatons (GT) of rice straw is generated in Sri Lanka per year (National Engineering Research and Development Centre of Sri Lanka, 2018). Regardless of this large amount and the recommendation of the Department of Agriculture of Sri Lanka to incorporate straw to the soil, farmers have found the best way of eliminating this waste as open field burning. However, this action has created a number of impacts due to the emission of greenhouse gases and other pollutants ( $\mathrm{CO}$ and fine dust particles) to the atmosphere which results in air pollution and can contribute for the global warming (Gadde et al.,2009). Therefore, the use of rice straw for the production of cellulose would be an effective way of value addition. Sri Lankan paddy cultivation employs a large number of rice varieties which can be mainly divided into two categories, traditional varieties and new improved varieties (NIVs). Traditional varieties are indigenous and known to be more nutritious than the latter (Herath et al., 1982). New improved varieties are the technically modified species which have been used in the large-scale commercial agriculture to obtain higher yields with improved resistance to pests and diseases (Dalrymple, 1986). Presently, growing of traditional varieties have increased due to the higher demand. This research work was conducted to isolate and characterize cellulose from two most widely cultivated traditional rice varieties in Sri Lanka.

\section{METHODOLOGY}

\section{Materials}

Rice straws of Raththal and Suwandel were collected at maturity after harvesting in 2016 Yala season from Hela Suwaya paddy cultivation area in Padaviya, Anuradhapura, and a traditional paddy cultivation area in Kurunegala, Sri Lanka, respectively. Toluene $\left(\mathrm{C}_{6} \mathrm{H}_{5} \mathrm{CH}_{3}, \geq 99.7 \%\right.$, ACS, Sigma-Aldrich), ethanol $\left(\mathrm{H}_{3} \mathrm{CCH}_{2} \mathrm{OH}\right.$, Min. $99.85 \%$, ACS, VWR Chemicals), acetic acid $\left(\mathrm{CH}_{3} \mathrm{COOH}, \geq 99.8 \%\right.$, ACS, Sigma-Aldrich), hydrogen peroxide $\left(\mathrm{H}_{2} \mathrm{O}_{2}, 50 \%\right.$ (w/v), AR, Glorchem), Sulfuric acid $\left(\mathrm{H}_{2} \mathrm{SO}_{4}, 95.0\right.$ - 97.0\%, ACS, Sigma-Aldrich), potassium hydroxide $(\mathrm{KOH}, \geq 85.0 \%$, GR, MERCK Chemicals) were used for the extraction of cellulose from rice straw. Purified water by Barnstead ${ }^{\mathrm{TM}}$ Smart2Pure ${ }^{\mathrm{TM}}$ water purification system was used in analysis (Thermo Fisher Scientific, Waltham, MA). 


\section{Pre-treatment of rice straw}

Initially, foreign materials such as dried grass, rice husk, and other plant residues were removed from rice straw. Rice straw $(200 \mathrm{~g})$ was thoroughly washed with warm water followed by twice in cold water to remove dirt and aqueous soluble substances. Cleaned rice straw was air dried at room temperature for $48 \mathrm{~h}$ followed by oven drying (Memmert $\mathrm{GmbH}$, Germany) at $60{ }^{\circ} \mathrm{C}$ for $5 \mathrm{~h}$. The dried and cleaned rice straw was milled using a grain grinder (SINGER, Sri Lanka) to obtain rice straw in powdered form. Sieve analysis of rice straw powder was done with the use of $250 \mu \mathrm{m}, 150 \mu \mathrm{m}, 106 \mu \mathrm{m}, 75 \mu \mathrm{m}, 53 \mu \mathrm{m}$ aperture sized screens. Then rice straw powder retained in each screen (except for $250 \mu \mathrm{m}$ screen) and pan were mixed together to obtain a homogeneous mixture.

\section{Extraction of cellulose}

The non-cellulosic materials in rice straw were removed to isolate cellulose by using following process. Rice straw powder $(10 \mathrm{~g})$ was first extracted in Soxhlet apparatus with 2:1, v/v toluene/ethanol $(450 \mathrm{~mL})$ mixture at $400{ }^{\circ} \mathrm{C}$ for $15 \mathrm{~h}$ to remove wax, pigments, and oils, followed by oven-drying at $55{ }^{\circ} \mathrm{C}$ for $24 \mathrm{~h}$. The dewaxed powder was then immersed in 3:10 (v/v) $\mathrm{H}_{2} \mathrm{O}_{2} / \mathrm{CH}_{3} \mathrm{COOH}$ solution with solid:liquid ratio $1: 60(\mathrm{w} / \mathrm{v})$ at $70{ }^{\circ} \mathrm{C}$ for $3 \mathrm{~h}$ to dissolve lignin. $\mathrm{H}_{2} \mathrm{SO}_{4}$ was used as a catalyst. Extraction mixture was stirred constantly at $125 \mathrm{rpm}$. The insulated flask containing the chemical mixture was heated with water from the thermostatically-controlled water bath. During initial stages of stirring, oxygen evolution was active, and substantial frothing occurred, therefore extractions were conducted in a flask with volumes two to three times those of extraction mixtures. The insoluble residue was collected by vacuum filtration (Whatman 1, Maidstone,Kent, England), washed with deionized water until the $\mathrm{pH}$ of the filtrate was neutral and then dried at $60{ }^{\circ} \mathrm{C}$. Hemicellulose and silica in the delignified powder were leached with $110 \mathrm{~mL} \mathrm{5 \%} \mathrm{KOH}$ at room temperature for $24 \mathrm{~h}$ and then at $90{ }^{\circ} \mathrm{C}$ for $2 \mathrm{~h}$. The insoluble residue was collected by vacuum filtration (Whatman 42 , Maidstone, Kent, England), washed with deionized water until the $\mathrm{pH}$ of the filtrate was neutral, and then oven dried to remove water. Then the dry weight of the isolated cellulose was measured. All the tests were carried out in triplicate.

\section{Characterization Methods}

\section{Optical Microscopy}

Unbiasedly spread distributions of rice straw powder were imaged under an optical microscope (MT, Meiji Techno Co. Ltd, Japan) at 50X. The area distributions of rice straw powder from above four varieties were analyzed using an image processing software. Fourier-Transform Infrared Spectroscopy (FTIR) spectra of the rice straws before and after each chemical treatment were acquired using a Bruker ALPHA spectrometer (Bruker Corporation, Billerica, MA) at ambient conditions. Samples were prepared by grinding with $\operatorname{KBr}(1: 100$, w/w $)$ and pressing into transparent pellets. The spectra were obtained in the transmittance mode from an accumulation of 128 scans at a $4 \mathrm{~cm}^{-1}$ resolution over $4000-600 \mathrm{~cm}^{-1}$ range.

\section{Scanning Electron Microscopy (SEM)}

The microstructures and surface morphologies of extracted cellulose were examined by a scanning electron microscope (EVO 18, Carl Zeiss AG, Germany). The samples were mounted on Aluminum stubs with conductive carbon tape and sputtered with gold under vacuum at 10 $\mathrm{mA}$ for 90 secs (Sc7620 sputter coating system). The samples were observed and imaged at $14.5 \mathrm{~mm}$ working distance and $20 \mathrm{kV}$ accelerating voltage. 


\section{RESULTS AND DISCUSSION}

\section{Particle size distribution of straw}

The micrographs of rice straw powder particles were analyzed by using the image processing tool to acquire a distribution of particle area. In this context, it was assumed that particle area is proportional to the particle size. Then the distribution was fitted into a lognormal curve using the graphing software. Identical grinding parameters were used for both Suwandel and Raththal varieties. The analysis showed that $84 \%$ particles of Suwandel, $72 \%$ particles of Raththal varieties were in the particle area range between 0-200 $\mu \mathrm{m}$ (Figure 1).
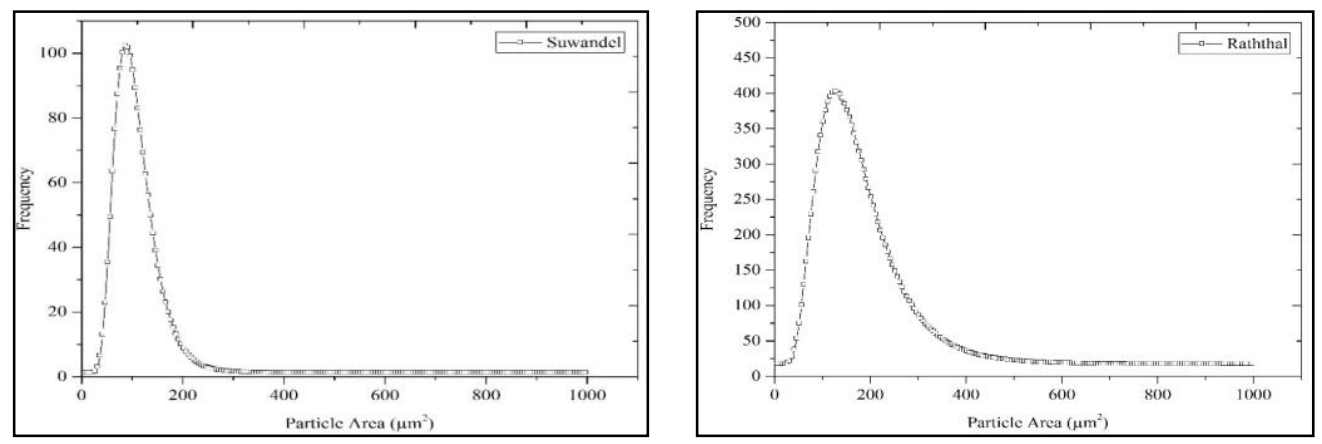

Figure 1. Particle area distribution of Suwandel (left) and Raththal (right) varieties

\section{Extraction of Cellulose from Rice Straw}

Rice straw is a lignocellulosic biomass (Kadam et al., 2000). Plant cell wall of such lignocellulosic materials has a complex composite structure which consists of cellulose fibers embedded in a matrix of organic polymers; hemicelluloses and lignin. Cellulose is the structural component that provides reinforcement to the plant (Chung et al., 2001). Other than that rice straw also contains inorganic materials which can be mainly categorized into insoluble ash (Silica) and soluble ash $\left(\mathrm{CaO}, \mathrm{MgO}, \mathrm{Na}_{2} \mathrm{O}, \mathrm{K}_{2} \mathrm{O}\right.$ etc.). Rice straw significantly differs from other cereal straws due to the high content of Silica (Pan et al., 1999). There is also a layer of cuticular wax, a complex mixture of different compounds functioning as a protective layer over the plant surface (Zhao et al., 2007). Hence, a much more sophisticated synthesis mechanism is required to isolate cellulose in high purity form for special applications. In this study, a step by step purification arrangement was designed to validate the complete and smooth removal of non-cellulosic constituents. Waxy substances in rice straw (sterols, spinasterone, aldehydes, ketones, chain alkanes etc.) (Buschhaus and Jetter, 2011) were initially removed by using toluene/ethanol mixture in Soxhlet extraction. This removal of protective layers also allows for the permeation of other chemicals into the plant in subsequent treatments. After that, a low environmental impact, oxidizing method known as peracetic acid treatment (Zhao et al., 2010) was utilized to eliminate lignin from rice straw. It should be noted that this method requires precise control of process parameters to achieve an optimum level of delignification and bleaching without degradation of cellulose structure. As the final step, the alkaline $\mathrm{KOH}$ treatment was used for the removal of hemicellulose and silica. Apart from above two components, pectin and other residual inorganic materials are also leached out through this process. In the end, cellulose with high purity was isolated from rice varieties 
(Figure 2). The pale brown colour of rice straws gradually reduced with each step to finally become white colour, which is characteristic to cellulose. Moreover, extracted cellulose appeared in hydrogel form due to its high affinity to absorb water.
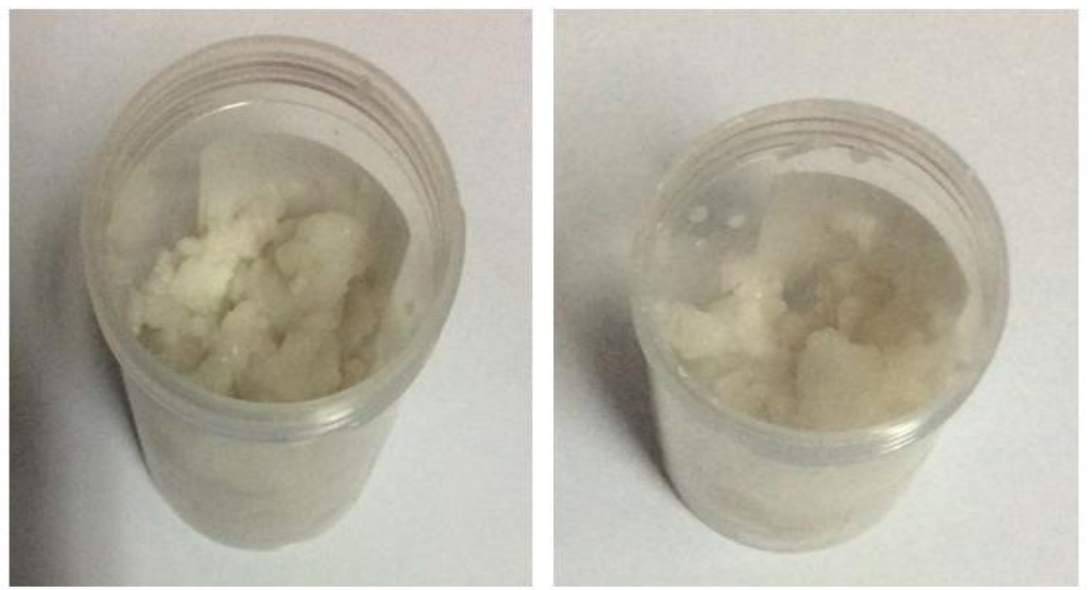

Figure 2. Extracted cellulose from Suwandel (left) and Raththal (right) rice straw varieties

The resultant white products acquired after chemical treatment of straw of different rice varieties were verified to be cellulose by FTIR spectra (Figure 3).

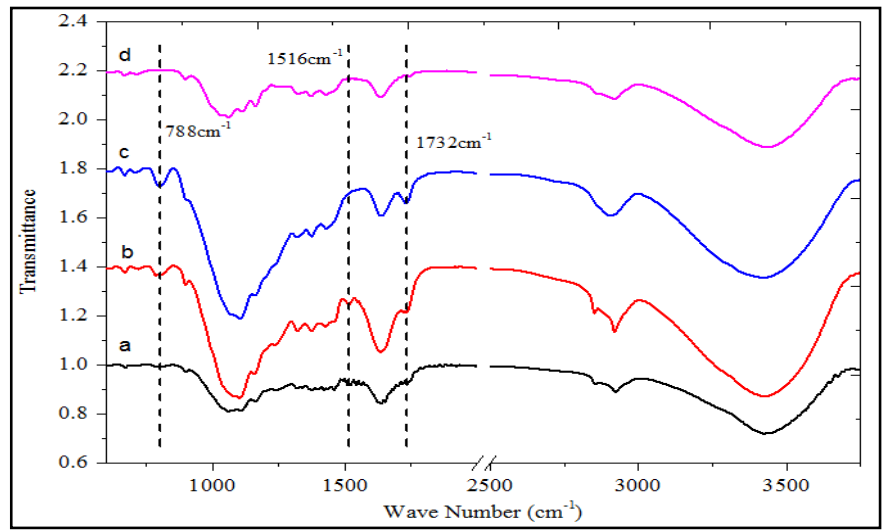

Figure 3. FTIR spectrums of rice straw during chemical purification process following: (a) cleaning (b) dewaxing (c) delignification, and (d) hemicellulose and silica removal

The spectra also clearly proved the sequential and complete removal of lignin $\left(1516 \mathrm{~cm}^{-1}\right.$ aromatic skeletal vibrations) (Pandey, 1999) during peracetic acid treatment and leaching of hemicellulose (1725 $\mathrm{cm}^{-1}$, carbonyl stretching) (Colom et al., 2003) and silica $\left(796 \mathrm{~cm}^{-1}, \mathrm{Si}-\right.$ O-Si stretching) (Lu \& Hsieh, 2012) during alkaline treatment (Figure 3). Extraction data revealed Suwandel and Raththal varieties contain approximately $35 \%$ and $25 \%$ of cellulose, respectively. 


\section{Morphological analysis of extracted cellulose}

SEM micrographs (Figure 4) of extracted cellulose showed that the material was in the form of fibers with a dimensional distribution over a wide range. It was estimated that fiber diameters are approximately in the range between 2-8 $\mu \mathrm{m}$. Micrographs also revealed that these cellulose fibers are in fact a bundle microfibrils which are strongly attached together with hydrogen bonds (Lavoine et al., 2012).

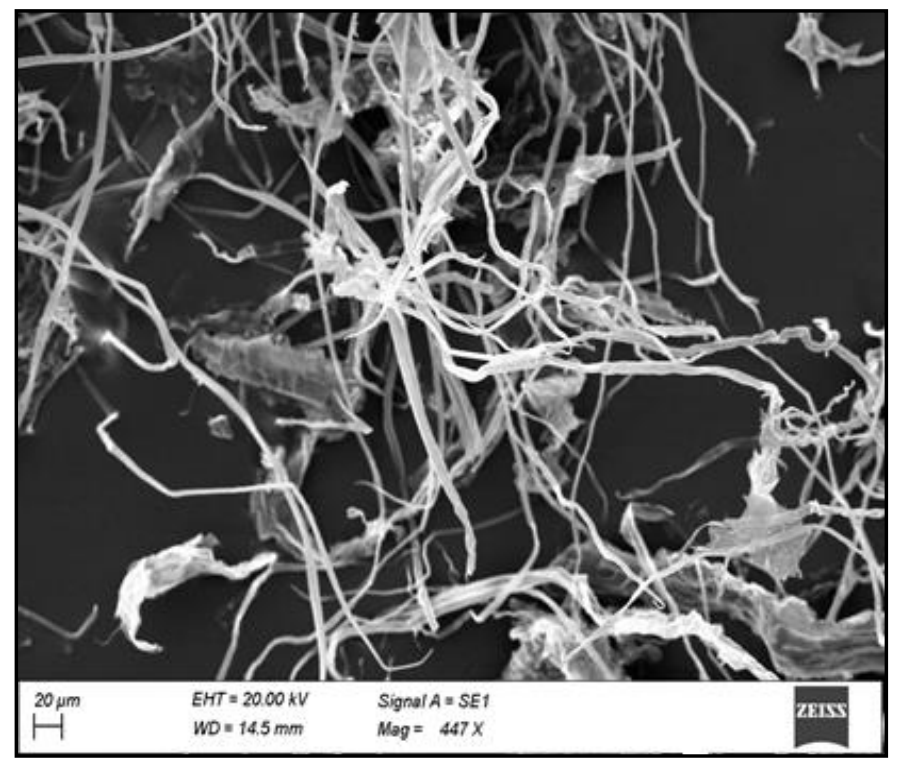

Figure 4. SEM Micrograph of cellulose extracted from Suwandel Rice Variety

\section{CONCLUSIONS}

Cellulose was successfully extracted with a satisfactory yield from the traditional rice varieties in Sri Lanka by employing the established non-cellulosic material removal process. Suwandel variety showed a considerably high cellulose yield which suggests that this variety could be a good source for commercial cellulose production compared to Raththal variety. This biopolymer has a huge potential as an alternative candidate for synthetic polymers in a wide spectrum of applications. Hence, the outcome of this research can be used as a solution for most of the concerns associated with agricultural waste management in Sri Lanka.

\section{REFERENCES}

Barnes, D.K., Galgani, F., Thompson, R.C. and Barlaz, M. (2009). Accumulation and fragmentation of plastic debris in global environments. Philosophical Transactions of the Royal Society B: Biological Sciences, 364(1526), 1985-1998. 
Brinchi, L., Cotana, F., Fortunati, E. and Kenny, J.M. (2013). Production of nanocrystalline cellulose from lignocellulosic biomass: technology and applications. Carbohydrate Polymers, 94(1), 154-169.

Buschhaus, C. and Jetter, R. (2011). Composition differences between epicuticular and intracuticular wax substructures: how do plants seal their epidermal surfaces?. Journal of Experimental Botany, 62(3), 841-853.

Chung, Y.M., Lee, J.C., Kim, K.S. and Eun, J.B.(2001). Chemical Compositions of 26Varieties of Korean Rice Straw. Food Science and Biotechnology, 10(3), 267-271.

Dalrymple, D.G. (1986). Development and spread of high-yielding rice varieties in developing countries,pp.1-10

Egodage, D.P., Jayalath, H.T.S., Samarasekara, A.M.P.B. and Amarasinghe, D.A.S. (2017), August. Fabrication of Antimicrobial Material for Food Packaging Applications. In Proceedings of International Forestry and Environment Symposium (Vol. 21).

Gadde, B., Bonnet, S., Menke, C. and Garivait, S. (2009). Air pollutant emissions from rice straw open field burning in India, Thailand and the Philippines. Environmental Pollution, 157(5), 1554-1558.

Geyer, R., Jambeck, J.R. and Law, K.L. (2017). Production, use, and fate of all plastics ever made. Science advances, Vol.3(7).

Habibi, Y., Lucia, L.A. and Rojas, O.J. (2010). Cellulose nanocrystals: chemistry, selfassembly, and applications. Chemical reviews, 110(6),3479-3500.

Herath, H.G., Hardaker, J.B. and Anderson, J.R. (1982). Choice of varieties by Sri Lanka rice farmers: comparing alternative decision models. American Journal of Agricultural Economics, 64(1),87-93.

Horikoshi, V.K.K.V.Y. (2005). Bio-based polymers. Fujitsu Sci. Tech. J, 41(2), 173-180.

Iwata, T. (2015). Biodegradable and bio-based polymers: future prospects of eco-friendly plastics. AngewandteChemie International Edition, 54(11), 3210-3215.

Kadam, K.L., Forrest, L.H. and Jacobson, W.A. (2000). Rice straw as a lignocellulosic resource: collection, processing, transportation, and environmental aspects. Biomass and Bioenergy, 18(5), 369-389.

Lavoine, N., Desloges, I., Dufresne, A. and Bras, J. (2012). Microfibrillated cellulose-Its barrier properties and applications in cellulosic materials: A review. Carbohydrate polymers, 90(2),735-764.

Lemieux, P.M., Lutes, C.C. and Santoianni, D.A., (2004). Emissions of organic air toxics from open burning: a comprehensive review. Progress in energy and combustion science, 30(1), 132.

Lu, P. and Hsieh, Y.L., (2012). Preparation and characterization of cellulose nanocrystals from rice straw. Carbohydrate Polymers, 87(1),564-573. 
Nanayakkara, M.P.A., Pabasara, W.G.A., Samarasekara, A.M.P.B., Amarasinghe, D.A.S. and Karunanayake, L., (2018), May. Extraction and Characterization of Cellulose Materials from Sri Lankan Agricultural Waste. In Proceedings of International Forestry and Environment Symposium (Vol. 22).

Pan, X.J., Sano, Y. and Ito, T. (1999). Atmospheric acetic acid pulping of rice straw II: behavior of ash and silica in rice straw during atmospheric acetic acid pulping and bleaching. Holzforschung, 53(1), 49-55.

Pandey, K.K., (1999). A study of chemical structure of soft and hardwood and wood polymers by FTIR spectroscopy. Journal of Applied Polymer Science, 71(12), 1969-1975.

Rios, L.M., Moore, C. and Jones, P.R. (2007). Persistent organic pollutants carried by synthetic polymers in the ocean environment. Marine Pollution Bulletin, 54(8), 1230-1237.

Rösler, J., Harders, H. and Baeker, M. (2007). Mechanical behaviour of engineering materials: metals, ceramics, polymers, and composites. Springer Science \& Business Media.

Samarasekara, A.M.P.B. and Jayasuriya, E.A.P.C.D. (2014), February. Synthesis of Biodegradable Polyolefins Based Polymer Composites Using Degradable Natural Materials. In Proceedings of International Forestry and Environment Symposium (Vol. 18).

Siró, I. and Plackett, D., (2010). Microfibrillated cellulose and new nanocomposite materials: a review. Cellulose, 17(3), 459-494.

Zhao, W., Zong, Z.M., Lin, J., Song, Y.M., Guo, X.F., Yao, Z.S., Zhang, L.N., He, R.L., Cao, J.P. and Wei, X.Y. (2007). Dewaxing from stalks with petroleum ether by different methods. Energy \& fuels, 21(2), 1165-1168.

Zhao, X., van der Heide, E., Zhang, T. and Liu, D. (2010). Delignification of sugarcane bagasse with alkali and peracetic acid and characterization of the pulp. BioResources, 5(3), 1565-1580. 